\title{
Annual variation in prey composition of domestic cats in rural and urban environment
}

\author{
Dagny Krauze-Gryz ${ }^{1}$ (D) Michał Żmihorski ${ }^{2} \cdot$ Jakub Gryz $^{3}$
}

Published online: 28 December 2016

(C) The Author(s) 2016. This article is published with open access at Springerlink.com

\begin{abstract}
The threat that domestic cats pose to wildlife has gained increased recognition by researchers and conservationists, and in this study, we investigated the seasonal variability and the effects of environment type (rural vs. urban) on the prey composition of free-ranging house cats in Poland. We analysed the variability in 307 monthly prey samples of different prey items killed by cats and brought to their owners (i.e., prey brought home by cats living in one home in one month) between 2002 and 2007 at 26 rural and urban sites. The variability in prey composition over time was analysed using additive models and canonical correspondence analysis. In total, we recorded 1348 prey items. Rodents were the most common prey in both environments, but shrews and reptiles were killed by cats more often in the rural environment while birds (mainly sparrows and pigeons) were more common in the urban environment. Additionally, prey composition changed seasonally. The pooled number of vertebrates killed by cats was largest in September and lowest in January, and rodents were killed most often in September, shrews and birds in June, and reptiles in April. The seasonal variation in the prey composition of cats was relatively high in the rural environment and more stable in the urban environment. Prey composition seemed to follow temporal and spatial variations in
\end{abstract}

Dagny Krauze-Gryz

dagny.krauze@wl.sggw.pl

1 Warsaw University of Life Sciences - SGGW, Nowoursynowska 159, 02-776 Warsaw, Poland

2 Institute of Nature Conservation, Polish Academy of Sciences, Mickiewicza 33, 31-120 Cracow, Poland

3 Forest Research Institute, Braci Leśnej 3, 05-090 Raszyn, Sękocin Stary, Poland prey availability, thus confirming a facultative feeding strategy in free-ranging house cats.

Key words Felis catus · Central Poland · Prey brought home · Season · Vertebrates $\cdot$ Rural to urban

\section{Introduction}

As medium-sized carnivores, domestic cats, Felis catus, are usually strictly associated with human settlements and have been introduced by humans all over the world. They are effective predators that mainly hunt small or medium-sized vertebrates (Fitzgerald and Turner 2000), and while the density of feral cats is directly correlated with prey abundance (Genovesi et al. 1995; Edwards et al. 2001), the population density of free-ranging house cats is more reflective of human density (due to the provision of supplementary food) than that of their prey (Sims et al. 2008). Consequently, cat populations reach high densities near human settlements, so they impose relatively strong hunting pressure on prey populations (Baker et al. 2005; Sims et al. 2008; Thomas et al. 2012). In urban areas in particular, cats are one of the most common avian predators (Sims et al. 2008), but their total impact on wildlife is difficult to estimate and varies greatly between studies (Fitzgerald and Turner 2000) and with study methodology (Krauze-Gryz et al. 2012a). Recently, however, cats have been estimated to kill between 100 and 350 million birds per year in Canada (Blancher 2013) and 2.4 billion birds and 12.3 billion mammals annually in the United States (Loss et al. 2013). In terms of overall proportions, they have been estimated to kill 2-7\% of all birds in southern Canada (Blancher 2013) and to be responsible for at least 30\% of sparrow deaths in an English village (Churcher and Lawton 1987). Introduced cats are 
responsible for the decline of native mammals in Australia (Risbey et al. 2000; Wheeler and Priddel 2009; Moseby et al. 2009; Frank et al. 2014), and several island studies have documented strong negative effects by cats on local endemic fauna (e.g., Fitzgerald and Veitch 1985; Medina and Nogales 2009; Bonnaud et al. 2012). These examples show, without a doubt, that both feral and free-ranging house cats should be considered a serious threat to biodiversity.

The evidence of the strong impact of cats on wildlife has focused the attention of conservation biologists towards possible methods of reducing that pressure. Consequently, many conservation initiatives have been aimed at the eradication of feral cats on islands (Nogales et al. 2004), but the threat that free-ranging house cats pose to wildlife is also serious and has gained recognition by both researchers and conservationists (e.g., Kays and DeWan 2004; Baker et al. 2005; Sims et al. 2008; Morgan et al. 2009; Bonnington et al. 2013). While there is a set of mitigation measures that can be considered (reviewed in Calver et al. 2011), the application of any of them requires cooperation with cat owners, who often fail to understand the detrimental effect their pets can have on wildlife (McDonald et al. 2015). Thus, studies showing the diversity of animal species that are killed by cats as well the magnitude of their hunting pressure are important; they both inform public opinion about the problem and can help raise financial support for mitigation. Most of the studies focused on the diet of free-ranging house cats have been conducted in the USA (Kays and DeWan 2004; Lepczyk et al. 2004), Australia and Oceania (Barrat 1997; Gillies and Clout 2003; Morgan et al. 2009; van Heezik et al. 2010). In Europe, where there is a relationship between high-density human populations and a high abundance of domestic cats, previous investigations were mainly located in the United Kingdom (i.e., Churcher and Lawton 1987; Woods et al. 2003; Baker et al. 2005; Thomas et al. 2012) but also in Sweden (Liberg 1984), Switzerland (Weber and Daily 1998; Tschanz et al. 2010), Poland (KrauzeGryz et al. 2012a) and Finland (Kauhala et al. 2015). However, this topic has never been investigated in many central and eastern European countries.

Previous studies have focused on the diets of free-ranging house cats to better understand their spatial and temporal variations (e.g., Barrat 1997; Baker et al. 2005; van Heezik et al. 2010; Kauhala et al. 2015), but several knowledge gaps still exist. The dietary composition of domestic house cats may differ from the empirical patterns observed in wild carnivores as most of house cats are supplementary fed by their owners, so they can continue to hunt a certain prey category even if the hunt is no longer profitable in terms of the costs-to-energy gain ratio. Furthermore, because of their reliance on artificial food sources, cats can substantially surpass the carrying capacity of the environment (reviewed in Kays and DeWan 2004). Consequently, even though food provisioning may reduce individual predation rates, the total impact of cat predation can be severe (reviewed in Baker et al. 2005). Furthermore, free-ranging house cats hunt in both natural habitats as well as close to human settlements (Kays and DeWan 2004; Goszczyński et al. 2008; Wierzbowska et al. 2012), and the latter group are typically avoided by many wild carnivores because of the presence of humans (Krauze-Gryz et al. 2012b). Finally, cats exhibit atypical hunting behaviour; i.e., they often kill and leave prey uneaten (Fitzgerald and Turner 2000; Krauze-Gryz et al. 2012a; Loyd et al. 2013). Because of these factors, the general picture of the variation in the prey composition of free-ranging cats is incomplete, especially in central and eastern Europe, leaving a high degree of uncertainty in terms of the total pressure of cats on wildlife.

In this study, we investigated the seasonal variability and the effects of two environments on the prey composition of free-ranging house cats in Poland. In previous studies, the diet composition and predation pressure of cats in natural and rural habitats have been contrasted with records from more transformed and built-up areas (e.g., Gillies and Clout 2003; Lepczyk et al. 2004; Kauhala et al. 2015), but few, if any, studies have addressed the seasonal variation in prey composition in this context (but see Kauhala et al. 2015). We attempted to do so and analysed the year-round variability in the different prey items killed by domestic cats at 26 sites in rural and urban environments, which provided us with the opportunity to separate the effects of time and the environment and to test the following three predictions. First, given the well-described shift in the diets of other generalist predators towards avian prey in urbanized areas, e.g., the tawny owl Strix aluco (Goszczyński et al. 1993; Zalewski 1994); the red fox Vulpes vulpes; or the stone marten Martes martes (reviewed in Bateman and Fleming 2012), we predicted that cats living in urban environments hunt birds with a higher frequency than rural cats. Second, we hypothesized that the prey composition of cats, which are generalist predators (Fitzgerald and Turner 2000), reflects changes in prey availability throughout the year, despite the supplementary feeding that these cats receive. Finally, we predicted that the annual variability in prey composition may differ between rural and urban environments as prey populations in these areas may follow different temporal dynamics.

\section{Methods}

\section{Study area}

The study was conducted in central Poland, a region that is affected by the mild oceanic climate of Western Europe and the harsh and dry continental climate of Eastern Europe and Asia. The duration of the growing season is c. 210 days; the total precipitation is $600 \mathrm{~mm}$ per year; and the mean ambient temperature ranges from $-4{ }^{\circ} \mathrm{C}$ in January to $+18{ }^{\circ} \mathrm{C}$ in July. 
We conducted the research in two environments: rural versus urban. The rural areas represented a typical field-forest mosaic with a prevalence of arable lands, in which woods of a few hundred hectares are surrounded by a fine mosaic of different crops, pastures, fallow land and stands of trees. Arable lands constitute $60-90 \%$ of the area, and the forest cover is much lower (6-30\%.) Villages (primarily consisting of a row of settlements along a road) and single farmsteads are evenly distributed at distances of no more than a few hundred metres from each other. Farms are typically small (i.e., most are 110 ha in size; Central Statistical Office-GUS data), and the population density is below 100 inhabitants $/ \mathrm{km}^{2}$. The urban environment was mainly represented by small towns in the vicinity and outskirts of Warsaw (i.e., its peripheral quarters), which is characterized by low buildings and houses with yards that are adjacent to green areas, such as parks or forests. However, the more central part of the city is densely built-up with tenements or blocks of flats with little green space that is mostly in the form of lawns located between buildings and sparse trees or shrubs. The population density is between 1000 and 4000 inhabitants $/ \mathrm{km}^{2}$, but in the central districts of the city, it can reach up to 8600 inhabitants $/ \mathrm{km}^{2}$. On the whole, the built-up areas cover approx. 50\%, arable lands and fallows $30 \%$, and forests $16 \%$ of the whole area of Warsaw.

\section{Collection of cat preys}

We collected the prey of cats belonging to 16 owners in rural and 10 owners in urban environments. Cat owners were recruited through door-to-door surveys in selected villages and through Internet forums, and they were asked to collect and record all of the prey that their cats brought home (Churcher and Lawton 1987; Gillies and Clout 2003; Baker et al. 2005). From October 2002 to December 2007, we collected data from the owners who cooperated with our study regularly for particular periods (between 1 and 43 months with an average of 12). In total, cats from 26 sites were monitored, and there were between 1 to 6 cats (1.8 on average) in a single site. All of the cats were active hunters and could leave their own settlements.

The cat owners were trained to recognize the most common prey species, and they used a data sheet to record all of the prey brought home and either froze the remains for storage or took photos for further assessment. The owners were also regularly contacted and assisted, and the data were collected at least once a month. Prey items were classified to the lowest possible taxonomic level (usually species or genus), but in some cases, i.e., if prey was not stored and we were not confident about the owner's ability to correctly identify the species, they were identified to order or class (e.g., 'rodentia unidentified', 'birds unidentified', etc.). In total, 17 detailed prey categories were distinguished (Table 1), but for the purpose of additive mixed modelling (see below), we grouped all
Table 1 Prey brought home by free-ranging domestic cats in rural and urban environments

\begin{tabular}{lrr}
\hline Prey category & Rural & Urban \\
\hline Muridae & 363 & 115 \\
Cricetidae & 181 & 24 \\
Rodentia unident. & 134 & 19 \\
Soricomorpha & 111 & 5 \\
Lagomorpha & 2 & 0 \\
Carnivora & 3 & 0 \\
Mammal unident. & 22 & 1 \\
Passeriformes & 73 & 63 \\
Piciformes & 1 & 0 \\
Columbiformes & 4 & 25 \\
Galliformes & 4 & 0 \\
Bird unident. & 23 & 16 \\
Lacerta agilis & 16 & 1 \\
Lacerta vivipara & 24 & 0 \\
Lacertilia unident. & 81 & 9 \\
Amphibia & 10 & 2 \\
Cypriniformes & 11 & 5 \\
Total & 1063 & 285 \\
\hline
\end{tabular}

of the prey items into five general categories: (1) rodents, (2) Soricomorpha (moles and shrews pooled), (3) birds, (4) reptiles and (5) all vertebrates pooled.

\section{Statistical analyses}

The variability in the five general prey categories collected by the cats was analysed using generalized additive mixed models (GAMM) with a Poisson error distribution and a $\log$ link. In the GAMMs, the number of prey items belonging to a given prey category in a given month, year and site was used as a response variable, and separate GAMMs were performed for each of these five categories (referred to as GAMMs 1 to 5). The models were based on a total of 307 monthly prey collections (i.e., prey brought by a cat or cats living in one site during one month) from 26 sites (i.e., cat owners) collected in 2002-2007. We used two explanatory variables in each GAMM: month (continuous variable, range: 1-12) and environment (categorical variable with two levels: rural vs. urban). The effect of month was fitted with a cyclic penalized cubic regression spline, i.e., splines whose ends match (Wood 2006), following the assumption that the response variable has similar values on the 31st of December and the 1st of January. We fitted the effect of month separately for the two environments (rural vs. urban) because the temporal dynamics of cat prey composition can differ between two environments. The number of knots for the spline fit was estimated to 5 to maintain a relatively simple fit. In each GAMM, site and year were used as random effects (the latter was fitted with a ridge penalty spline, 
which acts as a random effect but improves the robustness of the model, Wood 2006). Moreover, the total number of all preys varied between the monthly collections from different sites and years, reflecting both the willingness of the cats to hunt and the owners to cooperate with us. Thus, we used the total number of preys in a given collection as an offset (in GAMMs 1 to 4) to keep the response variable (e.g., numbers of rodents, birds, etc.), independent of the variation in collection sizes. In case of GAMM 5 (for which the total number of preys was used as response variable), the number of hunting cats in a given site, month and year was instead used as an offset (i.e., it was assumed to be a proxy of sampling effort). We based the parameter estimation on the full models computed using the "mgcv" package (Wood 2006) in R (R Core Team 2015).

The seasonal variation in prey was described according to four seasons: winter (December - February), spring (March - May), summer (June - August), autumn (September - November).

We performed and displayed a canonical correspondence analysis (CCA) to identify the major relationships between the composition of cat prey and the two environments. In this analysis, we used 17 detailed prey categories as the response variables, whereas environment (rural vs. urban) was used as an explanatory variable. The CCA controlled for the hypothetical differences between years, months and sites by including these three variables as conditions in the analyses; their effects were portioned out similarly to those of random factors in linear models (Oksanen et al. 2015). We tested the significance of the global model and the first two canonical axes with permutation tests with 5000 permutations. The analysis was performed using the 'vegan' package (Oksanen et al. 2015) in R.

\section{Results}

In total, we recorded 1348 prey items brought home by cats. Rodents were most common ( $n=836$ individuals) followed by birds (209), reptiles (131) and Soricomorpha (116). Mammals dominated cat prey in the rural environment (76.8\%) with birds and reptiles accounting for 9.9 and $11.4 \%$, respectively. In the urban environment, mammals accounted for approximately half of the prey killed, while birds were the second most common group (36.5\%). In both environments, rodents were the most common mammalian prey (accounting for $83.1 \%$ of mammals in the rural and 96.3\% in the urban environment) while soricomorphs composed 13.6 and $3.0 \%$ of mammalian prey, respectively. Murids were more frequently cat prey in urban than in rural environments $(72.8 \%$ vs. $53.5 \%)$ (Table 1$)$.

Soricomorphs and reptiles were killed significantly more often by cats living in rural than by those living in urban environments, while the reverse pattern was observed for birds (Table 2). There were no significant differences in the number of rodents and the pooled number of all vertebrates brought home by cats living in the two environments (Table 2).

Season was a significant predictor of the composition of prey brought home by domestic cats. Rodents were most frequently caught by cats in autumn; shrews, moles and reptiles were more frequent in summer; and birds were most commonly brought home by cats in spring. When vertebrates were pooled, the highest number killed by cats was observed in autumn and the lowest in winter, and the seasonal variation in the number of prey was always higher in the rural environment (Fig. 1). This was most distinctly the case for soricomorphs and birds; the shares of these prey categories showed no temporal variation in the urban environment (the splines for the urban environment were not significant, Table 2) but significant nonlinear variation in the rural environment (Table 2, Fig. 1).

Canonical correspondence analysis showed that most of the mammals killed by cats (except mice) were associated with the rural environment, and lizards also followed this pattern. The birds in the prey composition, including sparrows (Passer spp.) and pigeons (Columbiformes), were largely associated with the urban environment (Fig. 2).

\section{Discussion}

In our study, we confirmed all three of the predictions posed in the introduction. First, cats in urban areas hunted more birds compared to cats living in the rural environment. Second, temporal variations in the prey brought home by cats seemed to follow changes in prey availability throughout the year; rodents were most often brought home in the autumn (with a peak around September and October, when the highest densities were reached) and birds in the spring (with a peak around June, when the young leave the nests), while reptiles were caught least often during late autumn and winter (from November to February, when they are inactive). Third, the temporal dynamics of the prey brought home by rural and urban cats were clearly different. Therefore, our data suggest a facultative feeding strategy in free-ranging house cats.

However, it should be kept in mind that the methodological approach used in this study may be somewhat biased. When free-ranging cats hunt, they may injure, capture or kill their prey and either leave it in the field, consume it in the field or bring it home (Fitzgerald and Turner 2000), so methods that are based on consumed prey (scat/stomach content analyse) give different results than those based on prey brought home (Krauze-Gryz et al. 2012a). Indeed, cats usually kill more prey than they actually bring home (Loyd et al. 2013), so our study addressed only part of their hunting activity. Nevertheless, prey brought home may be assumed to be an index representing a minimum number of animals 
Table 2 Summary of generalized additive mixed models (GAMMs $1-5)$ explaining the numbers of the five prey categories brought home by free-ranging domestic cats. Estimated degrees of freedom (Edf) are given for splines, and significant effects are in bold

\begin{tabular}{|c|c|c|c|c|}
\hline Model & Predictor & Estimate (SE) & Statistic & $P$-value \\
\hline GAMM 1 & Intercept & $-0.32(0.28)$ & $t=1.1$ & 0.2600 \\
\hline Response: Rodents & Environment: rural & $0.34(0.35)$ & $t=1.1$ & 0.2530 \\
\hline \multirow[t]{2}{*}{$\mathrm{R}_{\text {adj }}^{2}=0.34$} & Month $_{\text {(rural) }}$ & $\mathrm{Edf}=2.75$ & $\mathrm{~F}=46.1$ & 0.0000 \\
\hline & Month $_{\text {(urban) }}$ & $\mathrm{Edf}=2.62$ & $\mathrm{~F}=9.0$ & 0.0000 \\
\hline GAMM 2 & Intercept & $-3.93(0.68)$ & $t=5.8$ & 0.0000 \\
\hline Response: Soricomorpha & Environment: rural & $2.37(0.73)$ & $t=3.3$ & 0.0013 \\
\hline \multirow[t]{2}{*}{$\mathrm{R}_{\text {adj }}^{2}=0.18$} & Month $_{\text {(rural) }}$ & $\mathrm{Edf}=1.85$ & $\mathrm{~F}=3.0$ & 0.0052 \\
\hline & Month $_{\text {(urban) }}$ & $\mathrm{Edf}=1.48$ & $\mathrm{~F}=1.5$ & 0.0506 \\
\hline GAMM 3 & Intercept & $-0.36(0.10)$ & $t=3.5$ & 0.0005 \\
\hline Response: Birds & Environment: rural & $-0.97(0.15)$ & $t=6.5$ & 0.0000 \\
\hline \multirow[t]{2}{*}{$\mathrm{R}_{\mathrm{adj}}^{2}=0.14$} & Month $_{\text {(rural) }}$ & $\mathrm{Edf}=1.78$ & $\mathrm{~F}=2.4$ & 0.0151 \\
\hline & Month (urban) & $\mathrm{Edf}=0.27$ & $\mathrm{~F}=0.1$ & 0.3234 \\
\hline GAMM 4 & Intercept & $-4.66(0.98)$ & $t=4.8$ & 0.0000 \\
\hline Response: Reptiles & Environment: rural & $2.43(1.11)$ & $t=2.2$ & 0.0298 \\
\hline \multirow[t]{2}{*}{$\mathrm{R}_{\text {adj }}^{2}=0.12$} & Month $_{\text {(rural) }}$ & $\mathrm{Edf}=2.83$ & $\mathrm{~F}=27.8$ & 0.0000 \\
\hline & Month $_{\text {(urban) }}$ & $\mathrm{Edf}=2.24$ & $\mathrm{~F}=3.2$ & 0.0091 \\
\hline GAMM 5 & Intercept & $0.58(0.27)$ & $t=2.2$ & 0.0313 \\
\hline Response: Vertebrates & Environment: rural & $0.40(0.34)$ & $t=1.2$ & 0.2372 \\
\hline \multirow[t]{2}{*}{$\mathrm{R}_{\text {adj }}^{2}=0.16$} & Month $_{\text {(rural) }}$ & $\mathrm{Edf}=2.95$ & $\mathrm{~F}=82.8$ & 0.0000 \\
\hline & Month $_{\text {(urban) }}$ & $\mathrm{Edf}=2.75$ & $F=11.5$ & 0.0000 \\
\hline
\end{tabular}

killed and can show a general pattern in cat diets (Woods et al. 2003; Tschanz et al. 2010). The other limitation of this study is the division of the relatively small number of sites $(n=26)$ divided into the two environments (rural vs. urban). A larger number of sites distributed across different levels of urbanization would allow us to investigate variation over the full urbanization gradient and test for possible nonlinear relationships between local habitats and the hunting ecology of cats.

As in previous studies (Churcher and Lawton 1987; Barrat 1997; Fitzgerald and Turner 2000; Woods et al. 2003; Kays and DeWan 2004; Morgan et al. 2009; Tschanz et al. 2010; Krauze-Gryz et al. 2012a), mammals (mostly rodents) dominated the prey brought home by cats in both studied environments. However, their dominance was far lower in the urban environment, where the share of birds in the prey clearly increased. Several former studies also indicate that pattern; in Finland, birds accounted for $24 \%$ of the prey of urban cats in contrast with $14 \%$ in the diet of rural cats (Kauhala et al. 2015). In the suburbs of Auckland (New Zealand), rodents dominated house cat kills in a habitat located on an urban/ forest fringe, while birds were the most commonly caught urban vertebrate prey (Gillies and Clout 2003). The observed differences in the composition of prey brought home by cats living in urban and rural environments most likely reflected prey availability, which was driven by differences in land-use. Within the bird group, the share of pigeons and sparrows in the prey brought home by cats was higher in the urban environment. Sparrows were also the most frequent (Gillies and Clout 2003; Morgan et al. 2009) or among the most frequent
Fig. 1 The predicted number of the five prey categories brought home per month by free-ranging domestic cats living in rural (solid curve) and urban environments (dashed curve) throughout the year. Curves represent cyclic spline fits (accompanied by $95 \%$ confidence intervals indicated by transparent areas) as predicted by the

GAMMs summarized in Table 2
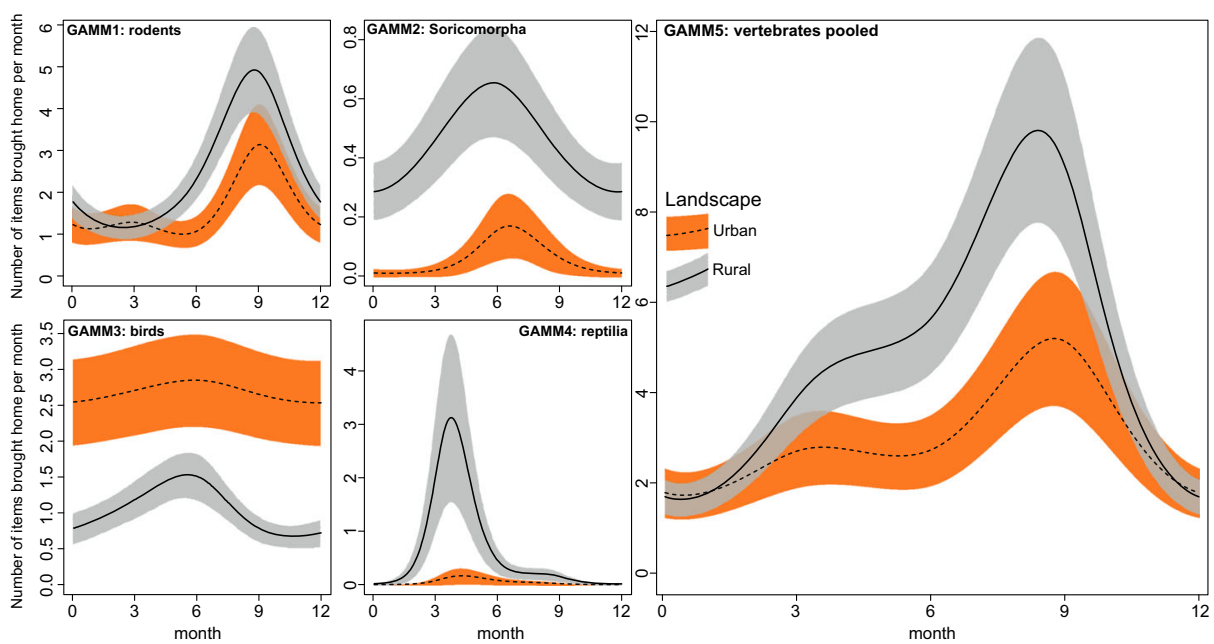


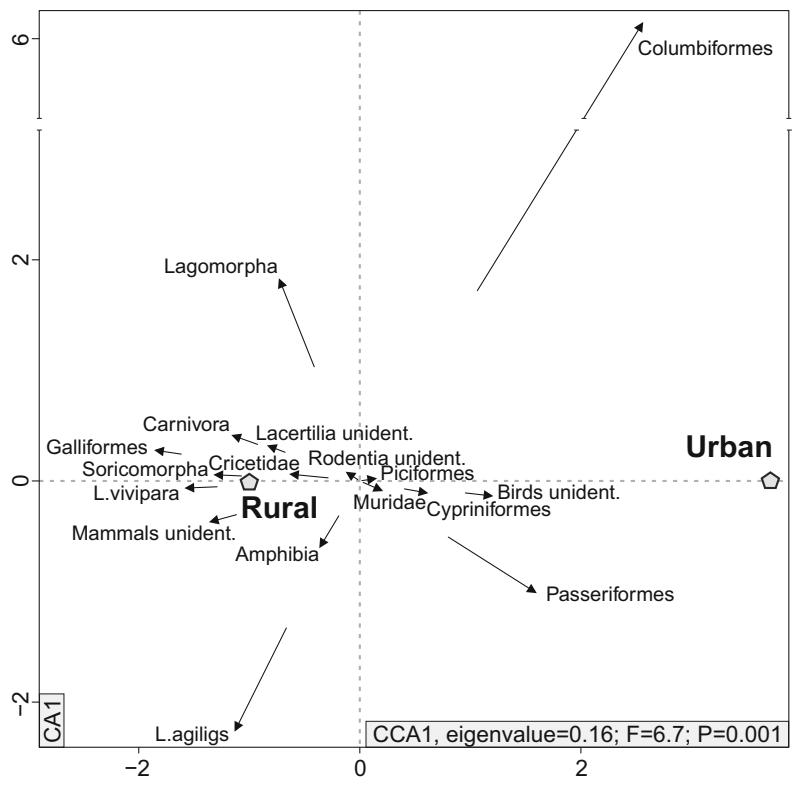

Fig. 2 Canonical correspondence analysis (CCA) showing the distribution of 17 prey categories brought home by free-ranging domestic cats in the two environments. The direction of the arrows indicates the correlation between prey category and environment type, and the length of the arrow indicates the strength of the correlation

(van Heezik et al. 2010) birds in urban and suburban habitats in New Zealand. Bird communities are usually less species rich in cities, but their abundance is relatively high compared to other environments (Rosin et al. 2016) with sparrows and pigeons being more common than in rural landscapes (Crooks et al. 2004). Thus, their share in the diet of opportunistic predators is usually higher in urban than rural environments, which was observed in studies of tawny owl (Goszczyński et al. 1993), martens and foxes (reviewed in Bateman and Fleming 2012).

Of the rodents killed by cats, the occurrence of mice was higher in the urban environment. Urbanization influences rodent species composition with the striped field mouse Apodemus agrarius, being a dominant species in considerably human-transformed habitats in Warsaw (BabińskaWerka et al. 1979; Gortat et al. 2014). Voles, on the other hand, are absent from the central quarters of Warsaw (Gryz et al. 2008), and their share in the rodent community decreases along an urbanization gradient (Andrzejewski et al. 1978; Gortat et al. 2014). Although populations of the striped field mouse reach very high densities in urban habitats, the species may be relatively difficult to catch due to dense vegetation (i.e., in parks, where rodents can hide in ivy cover), as observed for the tawny owl (Goszczyński et al. 1993). The two less common prey categories, soricomorphs and reptiles, also decreased in cat prey with increased urbanization. Our findings that the proportion of insectivores was higher in the rural than in the urban environment were similar to those of Kauhala et al. (2015).
Generally, shrews, being highly sensitive to fragmentation (Vergnes et al. 2013), are scarce in highly transformed, typically urban habitats (Andrzejewski et al. 1978; Gryz et al. 2008; Gortat et al. 2014).

We observed a clear temporal pattern in the composition of cat prey as different prey categories were caught in different proportions in different seasons. However, this seasonal variation was different in rural and urban environments, showing that urbanization affected the temporal patterns in the foraging ecology of cats. In our study, and similar to the results of other, rodents were most often caught in autumn and early winter (Barrat 1997; Weber and Daily 1998), and this variability is most likely driven by distinct changes in their abundance, which is the highest in autumn (Goszczyński 1977). Interestingly, this seasonal change in the number of rodents brought home by cats seemed to be smaller in the urban environment. According to Chernousova (2001), small mammal communities in cities are less dynamic, and rodent abundance remains relatively high compared to those in more natural areas. Another possible explanation for the autumnal increase in the numbers of rodents caught by cats in rural areas is their higher availability due to agricultural operations. After crops are harvested in the farmland (summer-autumn), rodents become much easier to hunt, and this is the time when cats more frequently penetrate fields (Goszczyński 1977; Krauze-Gryz et al. 2012b). The number of birds killed in rural areas fluctuated greatly, reaching a peak in spring (June) and a minimum in late autumn (November), while the number caught in the urban environment remained stable throughout the year. The peak in the number of birds killed by cats in rural areas, which primarily occurs in spring, probably reflects the killing of juveniles (e.g., Liberg 1984; Churcher and Lawton 1987; Barrat 1997; Baker et al. 2005; van Heezik et al. 2010), and several other generalist predators hunt birds most often during this season (e.g., Mirski et al. 2016). In winter, bird abundances are lower in rural areas due to seasonal migration, while in cities, most of the common species are sedentary (tree sparrow Passer montanus; house sparrow Passer domesticus; domestic pigeon Columba livia domestica), while migratory species are replaced by birds that winter in the city (e.g., Żmihorski et al. 2010); urbanization stabilizes winter bird communities (Suhonen et al. 2009). For example, birds can be hunted by cats next to bird feeders (Dunn and Tessaglia 1994). Woods et al. (2003) showed that cats living in households where birds were provided feed caught birds more often. The number of reptiles brought home by cats fluctuated greatly in rural areas. In the urban environment, where they were rather accidental prey, so the interseasonal change was rather small. Nevertheless, they appeared among the cat preys through spring and summer. Similarly, in Finland, reptiles were mainly brought home in the breeding season (Kauhala et al. 2015); in other seasons in the northern latitudes, when temperatures often drop 
below zero Celsius degrees, reptiles remain inactive and thus unavailable to cats.

Our study suggests that the two critical impact periods of cats on native fauna is spring (for birds) and autumn (for rodents), while during winter, cats catch fewer prey (especially in the rural environment) and are less active (Goszczyński et al. 2008). Thus, their overall predation pressure is relatively low. Rural cats, which are mainly kept as 'mousers' (Krauze 2008), are perceived as effective rodent killers, but in addition to killing synanthropic rodents, such as house mice Mus musculus, and rats Rattus spp., they prey on numerous species of voles as well as legally protected or rare species (e.g., shrews; hares Lepus europaeus; red squirrels Sciurus vulgaris; least weasels Mustela nivalis) (Krauze-Gryz et al. 2012a; this study). The effect of predation by free-ranging domestic cats on prey populations can be severe as their numbers are kept artificially high by supplemental feeding (Sims et al. 2008). At the same time, they do not show normal numerical or functional responses to prey density (Coleman and Temple 1993) as they switch between household food and natural prey depending on accessibility (Liberg 1984; Weber and Daily 1998). As a result, cats can efficiently compete with wild predators (Krauze-Gryz et al. 2012b). Urban and suburban cats mainly focus on birds, which results in serious predation rates (Lepczyk et al. 2004) or increases in sub-lethal factors, such as a reduction in fecundity (Beckerman et al. 2007) or food delivery to chicks (Bonnington et al. 2013). Special attention should be paid to the influence of house cats on the fauna of nature reserves located in or adjacent to cities or suburbs as the presence of free-ranging domestic cats, which are likely the most abundant predator, can reduce the effectiveness of these protected areas as a tool for protecting nature (Wierzbowska et al. 2012).

Acknowledgements We would like to thank Peter Lurz for his comments on the manuscript.

Open Access This article is distributed under the terms of the Creative Commons Attribution 4.0 International License (http:// creativecommons.org/licenses/by/4.0/), which permits unrestricted use, distribution, and reproduction in any medium, provided you give appropriate credit to the original author(s) and the source, provide a link to the Creative Commons license, and indicate if changes were made.

\section{References}

Andrzejewski R, Babińska-Werka J, Gliwicz J (1978) Synurbization processes in population of Apodemus agrarius. I. Characteristics of populations in an urbanization gradient. Acta Theriol 23:341-358

Babińska-Werka J, Gliwicz J, Goszczyński J (1979) Synurbization processes in population of Apodemus agrarius. II. Habitats of the striped-field mouse in town. Acta Theriol 24:405-415

Baker PJ, Bentley AJ, Ansell RJ, Harris S (2005) Impact of predation by domestic cats Felis catus in an urban area. Mammal Rev 35:302312. doi:10.1111/j.1365-2907.2005.00071.x
Barrat DG (1997) Predation by house cats, Felis catus (L.) in Canberra, Australia. I. Prey composition and preference. Wildl Res 24:263277. doi:10.1071/WR96020

Bateman PW, Fleming PA (2012) Big city life: carnivores in urban environments. J Zool 287:1-23. doi:10.1111/j.1469-7998.2011.00887.x

Beckerman AP, Boots M, Gaeston KJ (2007) Urban bird declines and the fear of cats. Anim Conserv 10:320-325. doi:10.1111/j.14691795.2007.00115.x

Blancher P (2013) Estimated number of birds killed by house cats (Felis catus) in Canada. Avian Conserv Ecol 8:3. doi:10.5751/ACE00557-080203

Bonnaud E, Berger G, Bourgeois K, Legrand J, Vidal E (2012) Predation by cats could lead to the extinction of the Mediterranean endemic yelkouan shearwater Puffinus yelkouan at major breeding site. Ibis 154:566-577. doi:10.1111/j.1474-919X.2012.01228.x

Bonnington C, Gaston KJ, Evans KL (2013) Fearing the feline: domestic cats reduce avian fecundity through trait-mediated indirect effects that increase nest predation by other species. J Appl Ecol 50:15-24. doi:10.1111/1365-2664.12025

Chernousova NF (2001) Specific features of the dynamics of murine rodent communities under the effects of urbanization: 1. Dynamics of species composition and abundance. Russ J Ecol 32:137-141

Churcher PB, Lawton JH (1987) Predation by domestic cats in an English village. J Zool 212:439-455. doi:10.1111/j.1469-7998.1987. tb02915.x

Calver MC, Grayson J, Lilith M, Dickman CR (2011) Applying the precautionary principle to the issue of impacts by pet cats on urban wildlife. Biol Conserv 144:1895-1901. doi:10.1016/j. biocon.2011.04.015

Coleman JS, Temple SA (1993) Rural residents' free-ranging domestic cats: a survey. Wildl Soc Bull 21:381-390 http://www.jstor. org/stable/3783408

Crooks KR, Suarez AV, Bolger DT (2004) Avian assemblages along a gradient of urbanization in a highly fragmented landscape. Biol Conserv 115:451-462. doi:10.1016/S0006-3207(03)00162-9

Dunn EH, Tessaglia DL (1994) Predation of birds at feeders in winter. J Field Ornithol 65:8-16

Edwards GP, de Preu N, Shakeshaft BJ, Crealy IV, Paltridge RM (2001) Home range and movements of male feral cats (Felis catus) an a semiarid woodland environment in Central Australia. Austral Ecol 26:93-101. doi:10.1111/j.1442-9993.2001.01091.pp.x

Fitzgerald BM, Turner CT (2000) Hunting behaviour of domestic cats and their impact on prey populations. In: Turner DC, Bateson P (eds) The domestic cat. The biology of its behaviour, 2nd edn. Cambridge University Press, Cambridge, pp. 151-176

Fitzgerald BM, Veitch CR (1985) The cats of Herekopare Island, New Zealand; their history, ecology and affects on birdlife. New Zeal J Zool 12:319-330. doi:10.1080/03014223.1985.10428285

Frank ASK, Johnson CN, Potts JM, Fisher A, Lawes M, Woinarski JCZ, Tuft K, Radford IJ, Gordon IJ, Collis M-A, Legge S (2014) Experimental evidence that feral cats cause local extirpation of small mammals in Australia's tropical savannas. J Appl Ecol 51:14861493. doi:10.1111/1365-2664.12323

Genovesi P, Besa M, Toso S (1995) Ecology of a feral Felis catus population in an agricultural area of northern Italy. Wildl Biol 1:233-237

Gillies C, Clout M (2003) The prey of domestic cats Felis catus in two suburbs of Auckland City. New Zeal J Zool 259:309-315. doi:10.1017/S095283690200328X

Gortat T, Barkowska M, Gryczyńska-Siemiątkowska A, Pieniążek A, Kozakiewicz A, Kozakiewicz M (2014) The effect of urbanization small mammal communities in a gradient of human pressure in Warsaw city, Poland. Pol J Ecol 62:163-172. doi:10.3161/104.062.0115

Goszczyński J (1977) Connections between predatory birds and mammals and their prey. Acta Theriologica 22:399-430 
Goszczyński J, Jabłoński P, Lesiński G, Romanowski J (1993) Variation in diet of tawny owl Strix aluco L. along an urbanization gradient. Acta Ornithol 27:113-123

Goszczyński J, Krauze D, Gryz J (2008) Activity and exploration range of house cats in rural areas of Central Poland. Folia Zool 58:363-371

Gryz J, Krauze D, Goszczyński J (2008) The small mammals of Warsaw as inferred from tawny owl (Strix aluco) pellet analyses. Ann Zool Fenn 45:281-285. doi:10.5735/086.045.0407

Kauhala K, Talvitie K, Vuorisalo T (2015) Free-ranging house cats in urban and rural areas in the north: useful rodent killers or harmful bird predators? Folia Zool 64:45-55

Kays RW, DeWan AA (2004) Ecological impact of inside/outside house cats around a suburban nature preserve. Anim Conserv 7:273-283. doi:10.1017/S1367943004001489

Krauze D (2008) Biocenotical role of domestic cat Felis silvestris catus in different types of field and forest mosaic. PhD thesis, Warsaw University of Life Sciences

Krauze-Gryz D, Gryz J, Goszczyński J (2012a) Predation by domestic cats in rural areas of Central Poland: an assessment based on two methods. J Zool 288:260-266. doi:10.1111/j.1469-7998.2012.00950.x

Krauze-Gryz D, Gryz JB, Goszczyński J, Chylarecki P, Żmihorski M (2012b) The good, the bad, and the ugly: space use and intraguild interactions among three opportunistic predators - cat (Felis catus), $\operatorname{dog}$ (Canis lupus familiaris), and red fox (Vulpes vulpes) - under human pressure. Can J Zool 90:1402-1413. doi:10.1139/cjz-2012-0072

Lepczyk CA, Mertig AG, Liu J (2004) Landowners and cat predation across rural-to-urban landscapes. Biol Conserv 115:191-201. doi:10.1016/S0006-3207(03)00107-1

Liberg O (1984) Food habits and prey impact by feral and house-based domestic cats in a rural area in southern Sweden. J Mamm 65:424 432. doi:10.2307/1381089

Loss SR, Will T, Marra PP (2013) The impact of free-ranging domestic cats on wildlife of the United States. Nature Comm 4:1396. doi: $10.1038 /$ ncomms 2380

Loyd KAT, Hernandez SM, Carroll JP, Abernathy KJ, Marshall GJ (2013) Quantifying free-roaming domestic cat predation using animalborne video cameras. Biol Conserv 160:183-189. doi:10.1016/j. biocon.2013.01.008

McDonald JL, Maclean M, Evans MR, Hodgson DJ (2015) Reconciling actual and perceived rates of predation by domestic cats. Ecol Evol 5:2745-2753. doi:10.1002/ece3.1553

Medina FM, Nogales M (2009) A review on the impact of feral cats (Felis silvestris catus) in the Canary Islands: implications for the conservation of its endangered fauna. Biodiv Conserv 18:829-846. doi:10.1007/s10531-008-9503-4

Mirski P, Krupiński D, Szulak K, Żmihorski M (2016) Seasonal and spatial variation of the Montagu's Harrier's diet in extensive farmland in eastern Poland. Bird Study 63:165-171. doi:10.1080 /00063657.2016.1143914

Morgan SA, Hansen CM, Ross JG, Hickling GJ, Ogilvie SC, Paterson AM (2009) Urban cat (Felis catus) movement and predation activity associated with a wetland reserve in New Zealand. Wildl Res 36: 574-580. doi:10.1071/WR09023

Moseby KE, Hill BM, Read JL (2009) Arid recovery - a comparison of reptile and small mammal populations inside and outside a large rabbit, cat and fox-proof exclosure in arid South Australia. Austral Ecol 34:156-169. doi:10.1111/j.1442-9993.2008.01916.x
Nogales M, Martín A, Tershy BR, Donlan CJ, Veitch D, Puerta N, Wood B, Alonso J (2004) A review of feral cat eradication on islands. Conserv Biol 18:310-319. doi:10.1111/j.1523-1739.2004.00442.x

Oksanen J, Blanchet FG., Kindt R, Legendre P, Minchin PR, O'Hara RB, Simpson GL, Solymos P, Stevens MHH, Wagner H (2015) vegan: Community Ecology Package. R package version 2.2-1. http://CRAN.R-project.org/package=vegan

R Core Team (2015) R: a language and environment for statistical computing. R Foundation for Statistical Computing, Vienna http://www. R-project.org/

Risbey DA, Calver MC, Short J, Bradley JS, Wright IW (2000) The impact of cats and foxes on the small vertebrate fauna of Heirisson prong, Western Australia. II. A field experiment. Wildl Res 27:223235. doi:10.1071/WR98092

Rosin ZM, Skórka P, Pärt T, Żmihorski M, Ekner-Grzyb A, Kwieciński Z, Tryjanowski P (2016) Villages and their old farmsteads are hot-spots of bird diversity in agricultural landscapes. J Appl Ecol 53:13631372. doi:10.1111/1365-2664.12715

Sims V, Evans KL, Newson SE, Tratalos JA, Gaston KJ (2008) Avian assemblage structure and domestic cat densities in urban environment. Divers Distrib 14:387-399. doi:10.1111/j.14724642.2007.00444.x

Suhonen J, Jokim ki J, Kaisanlahti-Jokim ki M-L, Hakkarainen H, Huhta E, Inki K, Suorsa P (2009) Urbanization and stability of a bird community in winter. Ecoscience 16:502-507. doi:10.2980/16-43280

Thomas RL, Fellowes MDE, Baker PJ (2012) Spatio-temporal variation in predation by urban domestic cats (Felis catus) and the acceptability of possible management actions in the UK. Plos One 7:e49369. doi:10.1371/journal.pone.0049369

Tschanz B, Hegglin D, Gloor S, Bontadina F (2010) Hunters and nonhunters: skewed predation rate by domestic cats in a rural village. Eur J Wildl Res 57:597-602. doi:10.1007/s10344-010-0470-1

van Heezik Y, Smyth A, Adams A, Gordon J (2010) Do domestic cats impose an unsustainable harvest on urban bird populations? Biol Conserv 143:121-130. doi:10.1016/j.biocon.2009.09.013

Vergnes A, Kerbiriou C, Clergeau P (2013) Ecological corridors also operate in an urban matrix: A test case with garden shrews. Urban Ecosystems 16:511-525

Weber JM, Daily L (1998) Food habits and ranging behaviour of a group of farm cats (Felis catus) in a Swiss mountainous area. J Zool 245: 234-237. doi:10.1111/j.1469-7998.1998.tb00096.x

Wheeler R, Priddel D (2009) The impact of introduced predators on two threatened prey species: a case study from western new South Wales. Ecol Manage Rest 10:117-123. doi:10.1111/j.14428903.2009.00457.x

Wierzbowska IA, Olko J, Hędrzak M, Crooks KR (2012) Free-ranging domestic cats reduce the effective protected area of polish national park. Mamm Biol 77:204-210. doi:10.1016/j.mambio.2012.01.004

Wood SN (2006) Generalized Additive Models: an introduction with R, CRC, Boca Raton

Woods M, McDonald RA, Harris S (2003) Predation of wildlife by domestic cats Felis catus in great Britain. Mamm Rev 33:174-188. doi:10.1046/j.1365-2907.2003.00017.x

Zalewski A (1994) Diet of urban and suburban tawny owl (Strix aluco) in the breeding season. J Raptor Res 28:246-252

Żmihorski M, Halba R, Mazgajski TD (2010) Long-term spatio-temporal dynamics of corvids wintering in urban parks of Warsaw, Poland. Orn Fenn 87:61-68 